\title{
JOB CHAINS AND WAGE CURVES: WORKER MOBILITY AND MARSHALLIAN SURPLUSES IN EVALUATING REGIONAL EMPLOYMENT GROWTH*
}

\author{
Joseph Persky \\ Department of Economics, University of Illinois at Chicago (M/C 144), 601 South \\ Morgan Street, Chicago, IL 60607. E-mail:jpersky@uic.edu
}

\section{Daniel Felsenstein}

Department of Geography, Hebrew University of Jerusalem, Mount Scopus, Jerusalem, Israel.E-mail: msdfels@mscc.huji.ac.il

\begin{abstract}
In theory, new regional jobs yield two distinct sources of welfare gains to workers: (1) mobility gains achieved by workers as they move up job chains and (2) traditional Marshallian surpluses enjoyed by all workers as labor markets tighten. In the past, we have argued that the second channel is likely to be small relative to the first. This paper integrates a chain model (using PSID job change data) with a modifiedMarshallian model based on "wage curves" (estimated from CPS data) to formalize and test that argument. High wage jobs with modest wage-unemployment elasticities show Marshallian effects only 10 percent to 20 percent the size of mobility effects. Low wage jobs with somewhat higher elasticities show Marshallian effects from 40 percent to 70 percent the size of mobility effects.
\end{abstract}

\section{INTRODUCTION}

State and local economic development efforts focus on creating jobs. But what is the appropriate way to measure the welfare gains generated by new jobs? Which groups in the regional labor market actually benefit from state and local job creation? The welfare gains to workers arising from local employment growth can be attributed to two broad sources. The first relates to the mobility gains accruing to workers through filling vacancies opened directly or indirectly by employment growth. In a local economy characterized by unemployment, underemployment, and a rigid wage structure, job mobility is the key to welfare gains. As local labor demand increases, job movers make gains. These gains accrue to both those who take the newly created jobs and those who fill vacancies opened up in the chain process. The approach that stresses vacancy chains and

*The Upjohn Institution provided generous support for our early work on job chains. In addition, we are grateful to Marlon Boarnet, Matthew Kahn, and three anonymous referees of this journal who have given us considerable assistance in refining our argument.

Received: January 2007; revised: September 2007; accepted: January 2008. 
returns to labor mobility as a primary source for worker's welfare gains has been articulated in Persky, Felsenstein, and Carlson (2004).

The second source of welfare gains is the Marshallian producer surplus, a source of rent evoked in more traditional labor market analyses (Marshall, 1920; Eberts and Stone, 1992). These gains accrue to workers who remain in their old jobs but experience real wage increases as labor markets tighten. An increase in demand will raise wage rates for an entire class of local workers and not just the mobile. Intuitively, the more elastic are local labor supplies, the smaller will be producer surpluses relative to mobility gains. This paper formalizes and tests this intuition by presenting an integrated approach to the two sets of gains.

We present an empirically based model of the regional labor market that combines these two welfare-generating mechanisms. Starting from a vacancy chains model, we measure welfare gains of those workers who take new jobs or move up into vacancies opened by job changers in the region. The paper suggests a new approach to integrating these estimates with consistent estimates for local workers experiencing wage increases. The key innovation in this approach is the re-interpretation of Marshallian surpluses as the change in area under wage curves of the Blanchflower and Oswald type. This allows us to use the chain model to estimate changes in regional unemployment rates which in turn are used to estimate changes in local wages via wage curves (by job category). Given a set of wage curves, these predicted unemployment rate changes imply changes in wage levels and hence allow an estimate of increased rents going to workers. These welfare gains are consistent with and in addition to worker gains achieved through mobility up regional job chains opened by new growth in labor demand.

The paper proceeds as follows. The next section reviews briefly the two literatures feeding the analysis, stressing the utility of each to the understanding of regional labor market processes. Section 3 presents the integrated model that underlies the central idea of the paper; the predictions of the job vacancy chains model for changes in unemployment rates. Section 4 then compares the empirical estimates of the relative size of mobility and producer surplus effects of increases in regional labor market demand. The relative sizes of these two effects depend critically on wage curve elasticities. Finally, Section 5 presents conclusions and speculations as to possible extensions.

\section{A TALE OF TWO LITERATURES}

Discussions of state and local economic development invariably focus on net employment gains and their effects on real wages. This is an approach that has characterized some of the key work on regional economic development (Topel, 1986; Bartik, 1991; Blanchard and Katz, 1992). Typically, employment change is specified in a demand equation as a function of lagged wages, group characteristics (education, demographic, ethnic), and some exogenous shock(s). Broad findings point to firms responding in the first instance by adjusting 
employment levels rather than by changing wages. Still, local labor market shocks are found to often affect the real wages of the less skilled. These studies have added much to our understanding of regional labor markets. However, they do not make explicit the welfare gains achieved by different market segments.

More recently, the estimation of welfare gains arising from the expansion of the local economy has increasingly focused on statistical issues such as controlling for the "right" reference group and accessing suitable data for quasiexperiments. Much effort has been expended on the judicious estimation of welfare change as expressed in changes in earnings or property prices (see, for example, Greenstone and Moretti, 2003). For all intents and purposes, such welfare changes are seen as emerging from a black box. Relatively little attention has been paid to clarifying the underlying model of welfare change in labor markets.

The present paper attempts a more structural approach. In this section, we outline the two main strands of the literature that underpin our integrated model of welfare gains arising from regional economic expansion: the job vacancy chains model and the wage curve model. At first glance, there does not seem to be much in common between the job chains model in which workers gain from filling vacancies opened up by job creation and the Marshallian perspective on labor rents in which producer surpluses accrue to workers who experience welfare gains as labor markets tighten. However, the two models can be conceptually linked through an integrated view of the effects of the growth of employment demand on unemployment.

The demand-driven vacancy chains model assumes involuntary unemployment and underemployment. An expansion of demand moves some workers up labor chains as it also draws on the currently unemployed, those out of the labor force and in-migrants from outside the region. In tracing these chains, such a model necessarily generates estimates of the decline in regional unemployment rates associated with regional employment expansion. If then we substitute wage-curves for the neo-classical supply curves of labor (one wage curve for each labor market segment), these reductions in unemployment rates can be translated into increases in wage rates. In a multisector wage curve model, these wage increases constitute Marshallian-like surpluses or rents.

In this way, the mobility-chain and the Marshallian-surplus conceptions of welfare gains can be integrated and consistently estimated for realistic (that is, less than perfect) regional labor markets. With the goal of actually operationalizing such an approach, we turn to a short introduction to chain modeling and a brief review of the wage curve literature.

\section{Job Vacancy Chains}

The crux of any "chain model" is the recognition that a move by an individual will predictably and relatively quickly affect other parts of the chain system. In a local labor market, a new job will generate a chain-like sequence of moves. For example, worker A moves to new job $i$ and vacates job $j$ for worker B who 
moves in, thereby vacating job $k$ for worker $\mathrm{C}$ and so on. In this system, mobility is induced by the vacancies that are created. New job $i$ becomes the starting point and mobility will continue through the chain until it is broken. This happens when a worker moves into a new job without offering any replacement position, for example, an in-migrant to the local area, an unemployed worker, or someone entering from out of the labor force.

The chain metaphor is readily applicable to analyses of housing markets (Forrest and Murie, 1994; Millard-Ball, 2002). As every house has an address, it is relatively straightforward to observe the upward and downward movement through individual housing units. In local labor market analysis, data is not generally collected on jobs as individual entities but rather on workers. The application of a job chains model must, therefore, be more indirect and has spawned a number of variants (vacancy-unemployment (V:U) studies, studies of job flows, churning studies, crowding-out studies etc.) Starting with the much-cited work of Holt and David (1966), labor economists have used vacancies, job searching, matching functions, and chain-like sequences in order to understand the vacancy-unemployment relationship in imperfect markets. Building on this approach, the "job flows" literature further develops the vacancy-unemployment model emphasizing the procyclical nature of job quits and the creation of vacancy chains in tight labor markets (Akerlof, Rose, and Yellen, 1988). Vacancy chains are shorter when unemployment is high as the probability of terminating the chain is high with so many job seekers available, who offer no job replacement. As opportunities expand, quits will increase and, therefore, quit behavior is procyclical.

As labor market "churning" is an intrinsic feature of job chains, "job flows" studies of labor market dynamics display another application of the chains theme. These studies suggest that in imperfect labor markets, flows are often important sources of adjustment (Blanchard and Diamond, 1992). Flows reflect high levels of mobility that are not captured in measures of net change. This labor turnover or "churning" indicates the existence of labor market mobility that is not captured by indices of net employment change. Much empirical evidence from a variety of countries (U.S., the Netherlands, and Germany) suggests that job chains are the source of this discrepancy (Burgess, Lane, and Stevens, 1996). Indeed, in the case of Germany, churning effects along job chains have been estimated to account for 50 percent of employment mobility in periods of tight labor demand (Schettkat, 1996).

A final application is in labor market "crowding" studies. Gorter and Schettkat (1999) have demonstrated that contrary to expectations, unemployed job seekers crowd-out the employed. They show that employed workers who find new jobs open up vacancy chains for the unemployed while the unemployed crowd out the employed. This is because job chains become shorter when the unemployed take vacancies and leave behind no replacement openings.

Given the existence of chain-related phenomena in much labor market activity, is there a rationale for adopting a chain perspective for regional labor markets? Elsewhere, we have argued that a chain model is well suited for 
measuring changes in economic welfare in local economies (Persky and Felsenstein, 2007). Chains are especially useful in markets where changes lead to the transmission of demand through a series of markets characterized by sticky prices, mark-ups, and mobility-driven rents (i.e., nonprice competition). Regional labor markets seem to fit this bill. They are often characterized by nonprice factors such as personnel policies, union contracts, public referral services, and a range of other institutional structures.

\section{Regional Wage Curves}

The empirical existence of a negative relationship between wages and unemployment (the wage curve) "discovered" by Blanchflower and Oswald (1994) and subsequently replicated in over 200 estimates for 30 countries (Nijkamp and Poot, 2005), has surprised many economists. For them, these results fly in the face of the expected equilibration of earnings as predicted by the HarrisTodaro (1970) model and the theory of compensating differentials (Roback, 1982). In attempting to explain the wage curve regularity, economists have resorted to noncompetitive theories of the labor market such as the efficiency wage model (Shapiro and Stiglitz, 1984), the union bargaining model (Townsend, 2005), the "lump sum" costs model (Campbell and Orszag, 1998), and the local monopsony model (Longhi, Nijkamp, and Poot, 2006). The key feature of the efficiency wage explanation is that lower unemployment rates in a local labor market require higher wages to maintain discipline. In the union bargaining model, unemployment decreases equilibrium wages by decreasing the value of the alternative wage and, therefore, disarms workers' threats to quit. The lump sum labor turnover costs model suggests that training and recruitment costs to firms in low unemployment labor markets encourage higher wages in order to offset the costs of workers quitting. To reduce labor turnover costs and facing an upward sloping supply curve, firms have an incentive to adjust wages across the business cycle. In the absence of these wage premia, tighter labor markets give workers greater incentives to slack, cheat, or threaten to quit since re-employment is more easily available.

While not generally emphasized, these explanations of the wage curve implicitly contain a theory of labor rents. An increase in local demand for labor results in an increase in wages for all workers, both those taking new jobs and those remaining in their existing employment. These wage increases are a welfare surplus for the workers. In principle, these gains can be calculated much as any producer surplus as an increase in the area above the supply curve (here the wage curve) and below the factor price.

The local monopsony explanation stresses the inherently spatial and local nature of the wage curve phenomenon. ${ }^{1}$ This boils down to the spillover interactions across local labor markets and the extent to which employees' discipline is mediated by employment opportunities in adjacent labor markets.

\footnotetext{
${ }^{1}$ For the case for a spatial basis for efficiency wages, see Mullen and Williams (2001).
} 
When workers face high mobility costs through changing jobs (job search, commuting, dislocation, etc), firms are likely to command a monopsonistic position in the local labor market (Longhi et al., 2006). The extent to which firms will offer wage increases or decreases in response to the level of unemployment, will be contingent on the alternative employment opportunities available regionally. Morrison, Papps, and Poot (2006) also introduce accessibility to other local labor markets as a key factor in estimating the employment elasticity of earnings. Their work estimates wage curves for 30 local labor markets in New Zealand and reports higher unemployment elasticities in more isolated areas. Thus, "first nature" influences may be a factor in promoting noncompetitive wage setting.

Another intrinsically spatial issue relates to the extent to which wage curves in regional labor markets respond to overall (national) unemployment rates or to regional (group or sector-related) influences. In the context of MSA's, Bartik (2000) has shown that overall MSA unemployment has more effect than own-group unemployment rates. Using both temporal and spatial fixed effects estimation on a data set for East Germany, Elhorst, Blien, and Wolf (2007) provide further empirical evidence that wage elasticities are conditioned by national and not just regional unemployment rates. In contrast, the evidence presented by Morrison et al. (2006) seems to suggest that the combination of group affiliation and (low level) personal mobility influence wage curves in local labor markets and local monopsony conditions would seem to exist for lower skilled and less mobile workers. Other studies have noted similar effects between groups of workers, for example, less wage elasticity among more educated workers (Card, 1995). However, no explicit spatial influences are addressed.

Finally, Gordon (2006) adds a further twist to the understanding of the wage curve as an inherently spatial phenomenon by claiming that this empirical regularity can be observed in competitive equilibrium when it is applied to local labor markets. These are characterized by openness and mobility between them that allows for the emergence of a positive wage-unemployment relationship. Conversely, the wage curve framework is not suitable in the national (closed economy) context. Using data for the U.K. travel to work areas, Gordon finds that vacancy rates rather than unemployment rates have the dominant (negative) relationship with earnings, further suggesting the local nature of the wage curve effect.

\section{MODELING WELFARE GAINS}

As suggested in the introduction, the model used here attempts to meld the chain approach with efficiency wage theory in an effort to provide a comprehensive view of the impact of new labor demand on workers' welfare. Figure 1 provides an overview of the approach. For the moment consider the "effective labor supply curve" to be a proxy for a traditional labor supply curve. Under this interpretation, workers can benefit from new demand $\left(L^{*}-L^{0}\right)$ in the figure, taken as an exogenous expansion, perhaps induced by policy in two ways. 


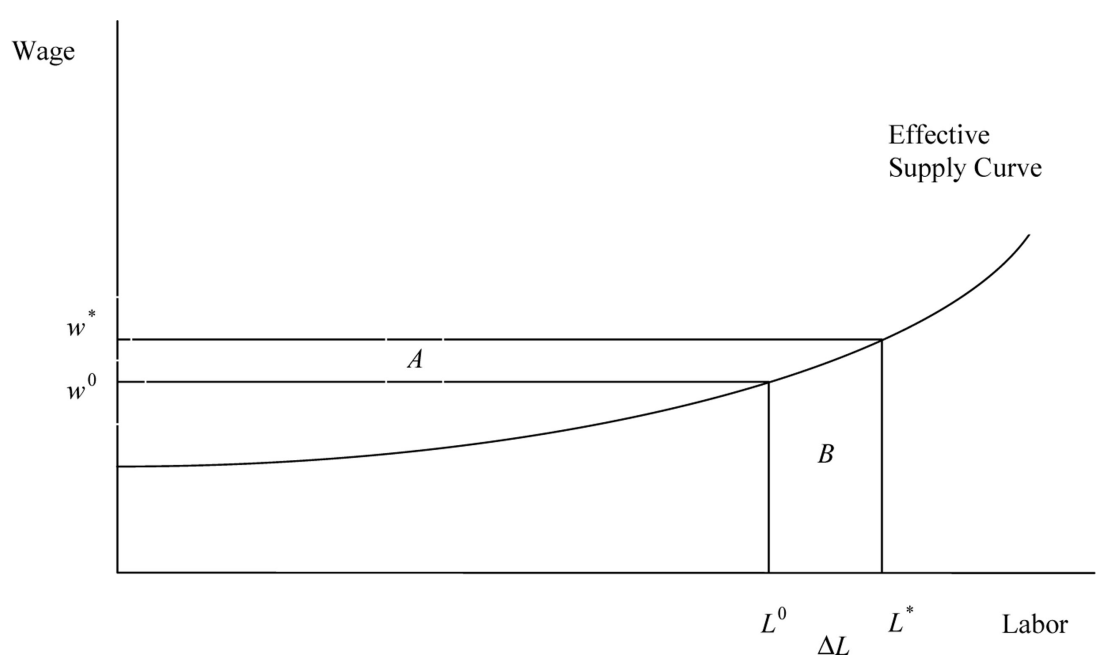

FIGURE 1: The Effective Labor Supply.

The area marked $A$ reflects the rise in wages in response to greater demand. $A$ is a Marshallian producer surplus shared by all employed workers as their wages rise. $B$ is the resource cost of new workers according to the supply curve. If, however, the true opportunity cost of the workers employed by the project is less than $B$ then they enjoy a welfare gain equal to some proportion, say $v$, of $B$. The goal then is to estimate $A$ and $\nu B$.

\section{The Chain Model and Mobility Gains}

The chain model is basically designed to trace mobility gains. For an expansion in a given labor market segment $j$ (defined in terms of relative wages), the chain model estimates the welfare gain generated to the job changers and newly employed as a result of their job mobility. It predicts in probabilistic terms all the transitions expected in the labor market chains generated by a newly created job in the segment. It then assigns a welfare gain to each of these transitions. Adding up over all transitions, weighted by their probability, it calculates $v_{j}$, the ratio of total mobility gains throughout the chains to the wage in the new job. $v_{j}$ can be interpreted as an estimate of $v_{j}$. This estimate does not take account of the rise in wages brought on by the new demand and thus might be regarded as a lower bound.

More specifically, the chain approach starts from a transition matrix, which reflects the (presumably) stable recruiting practices of employers in the various labor market segments. This matrix gives for each sector (column) the expected long run share of job recruits from each potential source. Table 1 suggests the layout of such a matrix.

The entries marked $q_{i j}$ is the share of recruits to jobs at level (column) $j$, which come directly from jobs at level (row) $i$. These are job movers responding 
TABLE 1: A Job Chains Matrix

\begin{tabular}{lccccc}
\hline \hline & \multicolumn{5}{c}{ New Wage Group } \\
\cline { 2 - 6 } Origin & 1 & 2 & 3 & 4 & 5 \\
\hline Wage group 1 & $q_{11}$ & $0.0 \%$ & $0.0 \%$ & $0.0 \%$ & $0.0 \%$ \\
Wage group 2 & $q_{21}$ & $q_{22}$ & $0.0 \%$ & $0.0 \%$ & $0.0 \%$ \\
Wage group 3 & $q_{31}$ & $q_{32}$ & $q_{33}$ & $0.0 \%$ & $0.0 \%$ \\
Wage group 4 & $q_{41}$ & $q_{42}$ & $q_{43}$ & $q_{44}$ & $0.0 \%$ \\
Wage group 5 & $q_{51}$ & $q_{52}$ & $q_{53}$ & $q_{54}$ & $q_{55}$ \\
Unemployed & $t_{u 1}$ & $t_{u 2}$ & $t_{u 3}$ & $t_{u 4}$ & $t_{u 5}$ \\
Not-in-labor force & $t_{n 1}$ & $t_{n 2}$ & $t_{n 3}$ & $t_{n 4}$ & $t_{n 5}$ \\
In-migrant & $t_{m 1}$ & $t_{m 2}$ & $t_{m 3}$ & $t_{m 4}$ & $t_{m 5}$ \\
Column sum & $100 \%$ & $100 \%$ & $100 \%$ & $100 \%$ & $100 \%$ \\
\hline
\end{tabular}

to higher wages and/or other incentives. The entries marked $t_{h j}$ show recruiting shares to jobs at level (column) $j$ from nonlocal job category $h$. These categories include the unemployed $(h=u)$, those not-in-the-labor-force $(h=n)$ and inmigrants $(h=m){ }^{2}$

A new job in any column initiates a chain reaction with probabilities suggested by the column entries. Subsequent vacancies then lead to further links in the chain according to their respective columns. A chain ends with a terminating event, hire from the unemployed, not-in-the-labor-force, or in-migrant category. Treating the matrix as a simple Leontief system allows the calculation of effective chain lengths (given by the Leontief inverse $[\mathbf{I}-\mathbf{Q}]^{-1}$ ) and the expected number of vacancies generated at each level. The key assumption throughout is that recruiting proportions for a vacancy at a given level depend on that level alone and not on the character of any particular chain.

To estimate welfare gains per new job in any category $j$, we simply add up the gains to every worker in the expected chain:

$$
v_{j}=\Sigma_{i} m_{i j}\left(w_{i} / w_{j}\right)\left[\left(\Sigma_{k} q_{k i} g_{k i}+t_{u i}\left(1-o c_{u i}\right)+t_{n i}\left(1-o c_{n i}\right)+t_{m i}\left(1-o c_{m i}\right)\right],\right.
$$

where $m_{i j}$ is the Leontief multiplier derived from a job chains matrix like that in Table $1, w_{i}$ is the wage for a job at level $i, q_{k i}$ is the entry on the $k$ th row and $i$ th column of the job chains matrix, $g_{k i}$ refers to the percentage wage gain in moving from job type $k$ to job type $i$, and $o c_{h i}$ stands for opportunity

${ }^{2}$ Note that not all job moves increase an individual's wage level. For wage groups $2-5$, a small fraction of all vacancies is filled by workers stepping down the wage hierarchy. It is difficult to conclude that such downward job changers are actually worse off for the presence of a vacancy at the level they ultimately find work. Presumably, in the absence of the vacancy they actually take, such downwardly mobile workers would have found a job at about the same low level, or perhaps lower. Thus, in our empirical work downward movers are allocated proportionally to all other categories. This is why the Q matrix is shown as triangular in Table 1. 
cost as a fraction of $w_{i}$, with $u, n$, and $m$ subscripts representing unemployed, out-of-the-labor-force, and in-migrant. ${ }^{3}$

Equations like (1) allow the estimation of the welfare benefits to those in job chains associated with job creation in sector $j$. In the present context, equation (1) can provide a straightforward estimate of $v_{j} B$, that is, $v_{j} w^{0} \Delta L$. These are ostensibly the welfare gains to job mobility in a less than perfect labor market. It should be emphasized that not all these gains accrue to those taking new jobs or even jobs at the same wage level. Much of the welfare gain accrues to those moving up chains at lower job levels.

\section{Wage Curves and Surpluses}

The theoretical problem, now, is to define a consistent estimate of workers' welfare gains achieved not by mobility but by increases in the sector wage rate as demand rises, that is, area $A$ in Figure 1. To maintain a reasonable degree of consistency, we must use an "effective supply curve" that allows for the existence of unemployment in the labor market sector. As suggested above, a natural way to achieve such consistency is to turn to the wage curve literature as an interpretation of labor markets with efficiency wages.

In its simplest form, a wage curve for a particular labor market sector, $k$, gives us a relation between $w_{k}$ and the region-wide unemployment rate, $u$. For example: $w_{k}=\alpha u^{-\beta}$, where $\alpha$ is a constant and $-\beta$ is the relevant elasticity. Armed with such a wage curve, if we want to estimate the change in $w_{k}, \Delta w_{k}$, resulting from a given growth rate in employment, $g=\Delta L / L^{0}$, we need to calculate the corresponding percentage change in the unemployment rate, $\Delta u / u^{0}$. A simple, but implausible, approach might assume that all the new employees come from the unemployed and that there was no change in the labor force, that is,

$$
\Delta u / u^{0}=\left(u^{*}-u^{0}\right) / u^{0}=\left[\left(U^{*}-U^{0}\right) / N^{0}\right] / U^{0} / N^{0}=-\Delta L / U^{0}=-g_{L}\left(1-u^{0}\right) / u^{0},
$$

where $U$ is the number of unemployed and $N$ is the size of the labor force. The problem here is obvious. It is well known that increasing the number of jobs in a region results in substantial in-migration to that region as well as an increase in labor force participation. Hence, $U$ will fall by less than $\Delta L$, and $N$ will increase. Both of these effects imply a smaller decrease in $u$ than suggested by the naïve forecast.

The critical observation, here, is that the chain model provides (at least first order) estimates of both the reduction in $U$ and the increase in $N$ that can be expected from a change in $L$ initiated in a given sector $j$. More specifically, in response to a change originating in the $j$ sector, $\Delta L_{j}$, we expect:

$$
\Delta U=-\Delta L_{j} \Sigma_{k} t_{u k} m_{k j},
$$

\footnotetext{
${ }^{3}$ Perhaps the most difficult parameters to estimate in (1) are the opportunity costs (oc ${ }_{j}$ 's) of the various terminal states in each column. Below, we try to link these opportunity costs to the expected unemployment rates for each type of worker.
} 
where $t_{u k}$ is the entry from the unemployment row and column $k$ of the job chains matrix, $m_{k j}$ is the vacancy multiplier from the Leontief inverse for $k$ level vacancies in response to a new $j$ level opening. This term represents the hiring of unemployed workers at level $k$ to fill either the initial or chain created vacancies at level $j$. Notice that depending on the coefficients in the $\mathbf{Q}$ matrix, the proportionality factor $\Sigma_{k} t_{u k} m_{k j}$ will vary across the different $j$ sectors. In general, it will be higher for lower wage sectors where more recruitment is done directly from the unemployed (and it will be lower for higher wage sectors where more recruitment is done through in-migration). ${ }^{4}$

At the same time, the labor force increases by the workers not drawn from the unemployed in the region:

$$
\Delta N=\Delta L_{j} \Sigma_{k}\left(t_{m k}+t_{n k}\right) m_{k j} .
$$

This expression will differ across sectors in a manner just the inverse of the unemployment relation. The term in the summation will tend to be lower for low wage sectors and higher for high wage sectors.

Using these two relations, we can now solve for $\Delta u / u^{0}$ as follows:

$$
\begin{aligned}
\Delta u / u^{0} & =\left(u^{*}-u^{0}\right) / u^{0}=\left[\left(U^{0}+\Delta U\right) /\left(N^{0}+\Delta N\right)-u^{0}\right] / u^{0} \\
& =\left[\left(1-g \Sigma_{k} t_{u k} m_{k j}\left(\left(1-u^{0}\right) / u^{0}\right)\right) /\left(1+\left(1+g \Sigma_{k}\left(t_{m k}+t_{n k}\right) m_{k j}\right)\left(1-u^{0}\right)\right)\right]-1,
\end{aligned}
$$

where $g$ is the growth rate of employment. ${ }^{5}$

Given $\Delta u / u^{0}$ we can use the elasticity of the wage rate in sector $k$ with respect to the unemployment rate (obtained from the wage curve) to calculate $\Delta w_{k} / w_{k}^{0}$. Our estimate of $A$ for sector $k$, the Marshall-like surplus defined in Figure 1, is then $\Delta w_{k} L_{k}^{0}$. As the unemployment rate falls, all sectors respond to the initial increase in sector $j$ employment. In a sector other than $j$, say $k$, the effective supply curve has shifted upward in response to the reduction in the labor force available to $k$ as workers have been recruited up the chains.

The key assumption here is that sector wage curves respond to the overall unemployment rate and not to specific sector unemployment rates. As noted above, some support for this proposition can be drawn from Bartik (2000) who suggests that wages in individual submarkets (central city/suburban, less than college/college, race) respond to the overall change in the unemployment rate and have no unique response to their own unemployment rate. He speculates this is because of the considerable interaction between submarkets.

${ }^{4}$ This feature of the model differs from work such as Bartik (1991), which (in our terms) implicitly assumes that all employment growth has the same wage group composition. This is an empirical prediction worth further investigation.

${ }^{5}$ Notice that all of the employment growth is in sector $j$. For the typical policy situation where growth crosses wage sectors (e.g., a subsidized manufacturing plant) an evaluator would have to calculate equation (2) separately for each expanding sector. The overall effect would then be the sum. 
We end this section by drawing attention to a key difference between mobility gains and general wage increases. Workers' welfare gains achieved through general wage increases are a transfer to workers from employers (and, perhaps, consumers of final products). This is not true of mobility gains, which represent efficiency improvements as workers reduce their underemployment. If employers (and/or consumers) have standing, then only the mobility gains should be included as net gains of the employment expansion. This is a complex question if we are focusing on state-level policy. Many, indeed, most of the owners and customers will live outside the state. But, whatever we conclude on the matter of standing, it is of considerable interest to compare the relative sizes of the two effects on workers, the question we turn to in the next subsection.

\section{EMPIRICS}

\section{Estimates of Mobility Gains}

For estimates of gains attributable to mobility, $v B$, we build on our previous work on job chains (Persky et al., 2004). The augmented $\mathbf{Q}$ matrix is based on a sample of job changers identified in the Panel Study of Income Dynamics (PSID) from the Survey Research Center in the Institute for Social Research at the University of Michigan. For the national PSID sample, about 600 individuals a year take new positions, with sufficient documentation to be included in the job mobility matrix. Of these, half are starting with a new employer. The sample includes all job takers 1987-1993. ${ }^{6}$

An in-migrant, here, is defined as any job taker who in the previous year lived in a different state or country. Thus, the resulting data can be interpreted as relating to a "representative" or "average" state. While metropolitan areas might more closely match "labor markets" and hence might be more appropriate economic units than states, policy making at the state level has been the driving force behind the lion's share of public economic development activity. There are few effective metropolitan-wide economic development agencies. At the state level, policy is very concerned with the secondary impacts of projects that spill over from one locality or metropolitan area to another. Hence, using states as basic units makes considerable sense from a policy perspective. ${ }^{7}$

Both new and old jobs are assigned to one of five real-wage groups. The highest of these runs from $\$ 25.50$ to $\$ 40$ per hour in 1992 prices, group 2 is

\footnotetext{
${ }^{6}$ It should also be noted that the PSID sample includes only household heads (including unrelated individuals with their own household) and their spouses. Other working members of households have insufficient job records to establish when job changes have been made. While heads and spouses are probably more stable than other household members, it isn't clear if this stability would bias the matrix.

${ }^{7}$ The mobility matrix presented here differs from that presented in Persky, Felsenstein, and Carlson (2004) which attempted a further division of states into metro and nonmetro portions. In addition to the policy argument made in the text, using a simpler state-based geography is consistent with the wage curves estimated below.
} 
TABLE 2: An Empirical Job Chains Matrix

\begin{tabular}{lccccc}
\hline \hline & \multicolumn{5}{c}{ New Wage Group } \\
\cline { 2 - 6 } Origin & 1 & 2 & 3 & 4 & 5 \\
\hline Wage group 1 & $q_{11}=41.7 \%$ & $0.0 \%$ & $0.0 \%$ & $0.0 \%$ & $0.0 \%$ \\
Wage group 2 & $q_{21}=27.0 \%$ & $q_{22}=53.2 \%$ & $0.0 \%$ & $0.0 \%$ & $0.0 \%$ \\
Wage group 3 & $q_{31}=4.8 \%$ & $q_{32}=23.4 \%$ & $q_{33}=49.2 \%$ & $0.0 \%$ & $0.0 \%$ \\
Wage group 4 & $q_{41}=2.2 \%$ & $q_{42}=1.5 \%$ & $q_{43}=20.0 \%$ & $q_{44}=49.2 \%$ & $0.0 \%$ \\
Wage group 5 & $q_{51}=0.0 \%$ & $q_{52}=0.3 \%$ & $q_{53}=2.4 \%$ & $q_{54}=13.3 \%$ & $q_{55}=36.3 \%$ \\
Unemployed & $t_{11}=2.9 \%$ & $t_{12}=4.1 \%$ & $t_{13}=10.7 \%$ & $t_{14}=16.6 \%$ & $t_{15}=26.0 \%$ \\
Not-in-labor force & $t_{21}=5.3 \%$ & $t_{22}=4.6 \%$ & $t_{23}=8.1 \%$ & $t_{24}=14.0 \%$ & $t_{25}=32.3 \%$ \\
In-migrant & $t_{31}=16.1 \%$ & $t_{32}=13.0 \%$ & $t_{33}=9.7 \%$ & $t_{34}=6.3 \%$ & $t_{35}=5.4 \%$ \\
Column sum & $100 \%$ & $100 \%$ & $100 \%$ & $100 \%$ & $100 \%$ \\
\hline
\end{tabular}

then $\$ 16.40$ to 25.50 , group 3 is $\$ 10.50$ to $\$ 16.40$, group $4 \$ 6.70$ to $\$ 10.50$, and group $5 \$ 4.25$ to $\$ 6.70$. While somewhat arbitrary, each group's lower bound is approximately two-thirds of its upper bound.

Table 2 presents our basic estimates, drawing on the entire period 19871993.

Each column in the table shows the "input vector" for the corresponding job group. An element in a column gives the proportion of the column vacancies filled from that origin row. Every column sums to 100 percent.

Starting with job vacancies in the highest wage group, as reported in Column 1, the element in the top row tells us that about 42 percent of vacancies at this level are taken by individuals who already have a job in the same group. About 27 percent of the vacancies go to workers employed in the second wage group and switching up to higher paid jobs in the first group. As we might well expect, workers holding jobs in groups 3 and 4 take few vacancies in the top group, and workers in group 5, take virtually none. The unemployed and those out of the labor force are also relatively unimportant recruiting fields for these high end jobs. However, a considerable share of group 1 vacancies, about 16 percent, go to in-migrants from out of state.

To use this matrix to estimate the $v_{j}$ 's as in equation (1), we need first to estimate the Leontief type multipliers, $m_{i j}$ 's. This just requires inverting the (I-Q) matrix. The results are given in Table 3. Each entry in the table gives the number of gross vacancies generated at that row level from a newly created job in that column. The last row, labeled "all groups" is simply the column sum.

Finally, we need estimates of the opportunity costs for the employed, not of the labor force and in-migrants, who take vacancies in the region. We begin by estimating sector unemployment rates. We assume that the unemployed hired into a job of a given wage class are drawn randomly from the unemployed population with a predicted wage at that group's level. Predicted wages are calculated from a standard human capital equation using individual characteristics of employed workers. Unemployed workers are then assigned a 
TABLE 3: Disaggregated Multiplier Matrix

\begin{tabular}{lccccc}
\hline \hline & \multicolumn{5}{c}{ Initial New Job } \\
\cline { 2 - 6 } Wage Groups & 1 & 2 & 3 & 4 & 5 \\
\hline Wage group 1 & $\mathbf{1 . 7 2}$ & 0.00 & 0.00 & 0.00 & 0.00 \\
Wage group 2 & 0.99 & $\mathbf{2 . 1 4}$ & 0.00 & 0.00 & 0.00 \\
Wage group 3 & 0.62 & 0.88 & $\mathbf{1 . 9 7}$ & 0.00 & 0.00 \\
Wage group 4 & 0.34 & 0.37 & 0.66 & $\mathbf{1 . 9 7}$ & 0.00 \\
Wage group 5 & 0.10 & 0.12 & 0.20 & 0.39 & $\mathbf{1 . 5 7}$ \\
All groups & 3.77 & 3.71 & 2.98 & 2.40 & 1.57 \\
\hline
\end{tabular}

TABLE 4: Efficiency and Distributional Effects

\begin{tabular}{cccccc}
\hline \hline & \multicolumn{5}{c}{ Wage Group of Initial New Job } \\
\cline { 2 - 6 } & 1 & 2 & 3 & 4 & 5 \\
\hline$v_{j} / w_{j}$ & 0.42 & 0.40 & 0.45 & 0.54 & 0.63 \\
\hline
\end{tabular}

predicted wage based on their own characteristics. Hence, an unemployment rate can be calculated for each wage sector. These rates are then normalized to give an overall rate of 5.3 percent using 1992 shares for employment.

Up to 2.5 percent of a sector's unemployment is considered voluntary; over 2.5 percent, it is considered as involuntary. The opportunity cost for a new worker hired from the unemployed is then taken as a weighted average of the opportunity costs of the voluntarily and involuntarily unemployed:

$$
o c_{i}=\left(1-\left(.025 / u_{i}\right)\right) * o c_{i \text { involuntary }}+\left(.025 / u_{i}\right) * o c_{i \text { voluntary }}
$$

where $o c$ refers to opportunity cost, $i$ is the wage group, and $u_{i}$ is the calculated unemployment rate of that wage group. For $o c_{i}$ involuntary we use the value 0.25

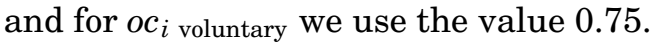

The resulting opportunity costs, $o c_{i}$ 's, given by this approach seem plausible. The highest two groups have values of 75 percent, group 3 is 66.7 percent, group 4 is 50 percent, and group 5 is 37.5 percent. These opportunity costs play the same role for those drawn from unemployment that original wages play for job changers. We use the same opportunity cost estimates for those coming from outside the labor force and in-migrants.

Armed with these opportunity costs we can generate estimates of the $v_{j}$ 's using equation (1). These are presented in Table 4, which closely parallel our results in Persky et al. (2004). Again $v_{j}$ is meant to represent the welfare gain to workers involved in a job chain initiated by a new job at level $j$. It is presented as a share of the level $j$ wage, $w_{j}$. Many state development agencies eagerly point to new wages in subsidized establishments as the benefit of their activities. 


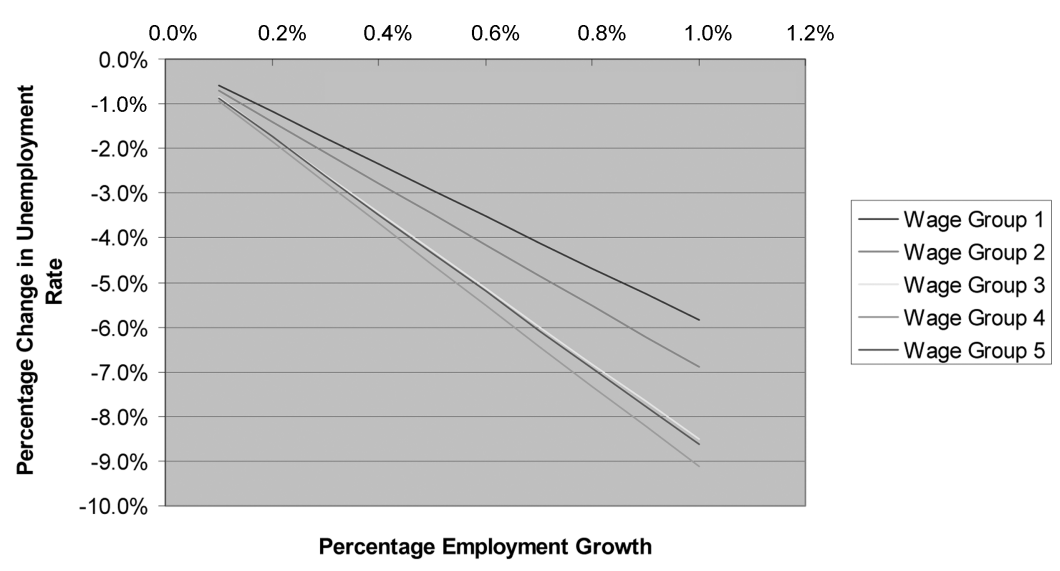

Note: A 5 percent change in a 5 percent unemployment rate reduces it to 4.75 percent.

FIGURE 2: Effects of Employment Growth Rate on Percentage Change in Unemployment Rate by Initiating Wage Group.

Presenting the welfare gain as a share of the initial wage makes clear the appropriate discount to such measures. ${ }^{8}$

On average the $v_{j}$ 's equal about half the wage rate. As can be seen, the estimated welfare gains for low wage jobs are a much higher share of the corresponding wage rate than for high wage jobs, reflecting the higher proportion of low wage jobs going to those in involuntary unemployment.

\section{Estimates of Wage Rate Increases}

Given the augmented $\mathrm{Q}$ matrix, equation (2) allows us to estimate the expected reduction in unemployment rates from any expansion of employment $\Delta L_{j}$ in sector $j$. More specifically, we can take the values for $t$ 's and $m$ 's from the last section to calculate the percentage change in the unemployment rate associated with any specified growth in $L_{j}$. A little algebra shows that this percentage change will also depend on the initial unemployment rate $u$. Holding $u$ at the sector averages given above, $\Delta u / u^{0}$ is approximately linear in $\Delta L_{j} / L^{0}$. Figure 2 shows the exact outcomes consistent with our augmented $\mathbf{Q}$ matrix for employment growth originating in each $j$. Sectors 2,3 , and 4, with steeper curves generate larger reductions in the overall unemployment rate for the same absolute growth. Employment growth in Sector 4 shows the strongest effect on the overall unemployment rate because this relatively low wage sector recruits heavily from the unemployed. Sector 5 recruits more heavily from the

\footnotetext{
${ }^{8}$ Of course neither the wage bill nor the welfare gain calculated here can be attributed to state economic development projects if in the absence of the intervention the employment growth would have occurred anyway. This is the so-called "But-for" problem (Persky, Felsenstein, and Wiewel, 1997).
} 
TABLE 5: Wage/Unemployment Rate Elasticities by Occupational Groups

\begin{tabular}{lcl}
\hline \hline Occupation & $\begin{array}{c}\text { Corresponding } \\
\text { Wage Group }\end{array}$ & $\begin{array}{l}\text { Elasticity } \\
\text { Estimate }\end{array}$ \\
\hline Engineers & 2 & -0.02 \\
Construction trades & 3 & -0.01 \\
Machine operator & 4 & $-0.04^{* *}$ \\
Retail/personal service sales workers & 5 & $-0.03^{*}$ \\
\hline
\end{tabular}

${ }^{*}$ Significant at 5 percent level; ${ }^{* *}$ significant at 1 percent level.

unemployed, but even more heavily from those out of the labor force. The latter effects dampen somewhat the overall decline in the measured unemployment rate.

For any given $\Delta L_{j} / L^{0}$, we can now approximate the resulting $\Delta u / u^{0}$. Now, the key problem in estimating the " $A$ " surplus is what wage curves to use to translate these percentage changes in the overall unemployment rate into percentage changes in wage rates. As suggested above, there is considerable debate over the exact nature of wage curves at various skill levels. The key parameter here is the elasticity of wages with respect to unemployment. At the high end, the estimates of Blanchflower and Oswald (1994) generate an elasticity of about -0.1 , but their estimates apply to nominal wages and not real wages. Real estimates tend to be considerably smaller. Bartik's estimates of real wage effects generate elasticities between -0.01 and -0.1 in the range of 5 percent to 6 percent unemployment (Bartik, 2000).

For this study we have explored the wage/unemployment elasticity for four broad occupations corresponding roughly to our wage groups $2-5$. These four are engineers, construction trades, machine operators, and retail/personal service sales workers. No occupation group in the CPS falls into our highest wage group "on average." Using data from the outgoing rotation groups of the Current Population Survey for 1979-2002, ${ }^{9}$ we have estimated four wage curves, one for each occupational group. Each wage curve is estimated using state data. The unemployment rate is the overall state unemployment rate and not the occupational unemployment rate. ${ }^{10}$ Dummy variables are included in all equations for year and for state. The resulting elasticities are given in Table 5.

In what follows we use the significant point estimates of the elasticities for wage groups 4 and 5 . For the first three wage groups we use -0.015 the simple average of the point estimates for group 2 and 3.

\footnotetext{
${ }^{9}$ Using these years for the wage curves puts the sample period for the mobility matrix, 1987-1993 roughly at the center of the period.

${ }^{10}$ This approach is suggested by Bartik's finding that "own" unemployment rates are not as important as the more comprehensive rate for the entire labor market.
} 
TABLE 6: Mobility and Wage Effects:

In Response to 5,000 New Workers in the Initiating Sector

\begin{tabular}{lccccc}
\hline \hline & \multicolumn{5}{c}{ Initiating Sector } \\
\cline { 2 - 6 } & 1 & 2 & 3 & 4 & 5 \\
\hline Mobility effect* & $42.3 \%$ & $39.5 \%$ & $45.1 \%$ & $53.9 \%$ & $62.5 \%$ \\
Wage effect* & $4.0 \%$ & $8.1 \%$ & $15.8 \%$ & $26.1 \%$ & $39.6 \%$ \\
Wage effect/mobility effect & 0.10 & 0.22 & 0.41 & 0.57 & 0.69 \\
\hline
\end{tabular}

${ }^{*}$ Calculated as a share of initial wage bill of newly generated jobs in the initiating sector.

\section{Comparing Effects}

Using the estimates presented up to this point, it is relatively easy to compare the value of mobility and wage change effects resulting from growth in any of our representative state's employment sectors. Throughout this section, we take the initial share of each sector as equal to the approximate national share for 1992 as noted above. Starting with the highest wage sector $(j=1)$, we introduce a major economic development project, which increases total employment in that sector by 5,000 workers. ${ }^{11}$ As implied by the first column of Table 4, the mobility effect comes to 42 percent of the initial increase in the sector 1 wage bill. The wage effect (including all spillovers) totals 4.0 percent of the initial increase in the sector 1 wage bill. Thus, the traditional surplus in this case amounts to about 10 percent of the mobility gains. Table 6 gives corresponding figures for similar employment growth rates in each of the sectors.

The mobility effects expressed in terms of the initial wage bill rise for groups 4 and 5 where opportunity costs are lower. But the wage effects increase faster as the lower wage groups (4 and 5) recruit more heavily from the unemployed and have wage rates, which are more sensitive to unemployment rates. The wage effect peaks at 39.6 percent for group 5. For this group, wage effects amount to almost 70 percent of the mobility effects.

\section{Sensitivity Analyses}

In the above calculations, a number of key assumptions have been made, where our lack of empirical information has forced us to improvise. With respect to our mobility findings, the most important of these have been: (1) taking unemployment up to 2.5 percent as voluntary, (2) setting the opportunity cost of involuntary unemployment at 25 percent. Altering these assumptions does change the calculations, but preserves much of the qualitative character of the results.

${ }^{11}$ For a state with a total of five million workers this is an increase of 0.1 percent. Since all responses in the model are proportional to the initial stimulus the precise size of the stimulus is not crucial. 
TABLE 7: Sensitivity Analysis of Mobility Effects: In Response to 5,000 New Workers in the Initiating Sector

\begin{tabular}{lccccc}
\hline \hline & \multicolumn{5}{c}{ Initiating Sector } \\
\cline { 2 - 6 } & 1 & 2 & 3 & 4 & 5 \\
\hline Mobility effect (base case) & $42.3 \%$ & $39.5 \%$ & $45.1 \%$ & $53.9 \%$ & $62.5 \%$ \\
Mobility effect (3.5\% voluntary unemployment) & $41.3 \%$ & $37.2 \%$ & $38.2 \%$ & $45.8 \%$ & $57.5 \%$ \\
Mobility effect (higher opportunity costs) & $31.8 \%$ & $27.7 \%$ & $30.6 \%$ & $35.5 \%$ & $40.0 \%$ \\
\hline
\end{tabular}

${ }^{*}$ Calculated as a share of initial wage bill of newly generated jobs in the initiating sector.

TABLE 8: Sensitivity Analysis of Wage Effects:

In Response to 5,000 New Workers in the Initiating Sector

\begin{tabular}{lcrrrr}
\hline \hline & \multicolumn{5}{c}{ Initiating Sector } \\
\cline { 2 - 6 } & \multicolumn{1}{c}{1} & \multicolumn{1}{c}{2} & \multicolumn{1}{c}{3} & \multicolumn{1}{c}{4} & \multicolumn{1}{c}{5} \\
\hline Wage effect (base case) & $4.0 \%$ & $8.1 \%$ & $15.8 \%$ & $26.1 \%$ & $39.6 \%$ \\
Wage effect $(2 \times$ elasticity) & $7.8 \%$ & $15.7 \%$ & $30.7 \%$ & $50.8 \%$ & $77.2 \%$ \\
Wage effect/mobility effect $(2 \times$ elasticity) & 0.19 & 0.40 & 0.68 & 0.94 & 1.24 \\
\hline
\end{tabular}

${ }^{*}$ Calculated as a share of initial wage bill of newly generated jobs in the initiating sector.

The first row of Table 7 repeats the basic mobility findings from Table 6 . The next two rows report two sensitivity tests: (1) pushing the boundary between voluntary and involuntary unemployment up to 3.5 percent and (2) increasing the opportunity cost of the involuntarily unemployed from 25 percent up to 50 percent and of the voluntarily unemployed from 75 percent up to 90 percent. The first of these brings all estimates down, with its strongest impact in groups 3,4 , and 5 . The second sensitivity test is more dramatic. All columns fall by more than 10 percentage points. The falls, while large, leave the same basic pattern to the results.

Both of the above tests will increase the ratios of the wage effects to the mobility effect. These ratios will still rise throughout, but now for the lowest wage group the wage effect will just about equal the mobility effect. With less to gain from upward mobility at the lowest levels, wage increases become more important.

Of course, one could also question the elasticities we have used in calculating the wage effects. Blanchflower and Oswald have argued for an elasticity close to -0.1 , and hence, considerably larger than our estimates reported in Table 5. As a sensitivity analysis, we re-estimate the wage effects of our model doubling the estimated elasticities (Table 8). Not surprisingly, these higher elasticities just about double the wage effects. While this has only a modest effect on the impacts of growth in high wage employment, it substantially increases the impact at low wage growth. Indeed, with these large elasticities in wage groups 4 and 5, the wage effects are the same order of magnitude as the mobility effects. 


\section{DISCUSSION AND CONCLUSIONS}

The calculations of the last section provisionally demonstrate the feasibility of comparing mobility gains and producer surpluses arising from state employment growth. Our reading of these results is that mobility effects are considerably larger than the more classical surplus effects. When regional employment expands, both low- and high-wage workers gain more from being directly involved in job mobility than from market effects on wages. However, market wage changes are relatively stronger for low wage labor market segments. Perhaps not surprisingly, tightening unemployment rates matter more to lowwage workers than to high-wage workers.

Two issues concerning our estimates as presented above deserve attention in future work. The first relates to the size of demand shocks and the second to the issue of migration of the unemployed. On net, taking these two factors together, we suspect that our estimates of changes in Marshallian surpluses may be viewed as upper bounds. The rationale for this conclusion is as follows:

In the first instance, the wage curves used in our calculations have been estimated from cross-section and panel data with substantial variance. State efforts to expand employment are generally undertaken on a modest scale. But the wage curves do not allow for any minimum threshold effects. In the formal model used here, wage curve effects are determined continuously with wages moving up smoothly with declines in unemployment. We suspect, however, that in the context of state policy small changes in unemployment rates might not register in the wage setting systems of the efficiency wage world. This would suggest that the model might well overestimate the effects of relatively small changes in unemployment rates.

With respect to the migration of the unemployed, the recruitment matrix of the job chains model is used here to predict in-migration responses to job growth. But that recruitment model does not allow the migration of unemployed workers, since it focuses only on those taking vacancies. If job growth encourages some in-migrants who then fail to find employment, we have overestimated the effect of job growth on unemployment rates and hence on wages. Evidence from Bartik (1991) suggests that the long run unemployment rate change from employment growth is substantially less than our estimates here. This observation again points toward an overestimation of producer surpluses.

Taken together, these potential biases suggest that general wage increases play a smaller role in generating worker welfare than estimated above. Finally, we again emphasize that whereas mobility gains are largely efficiency gains from better employing the unemployed or underemployed, the surplus-wage gains come for the most part at the expense of profits (lower producer surpluses to owners) or consumers (lower consumer surplus associated with final sales). In terms of net benefits of a job creation program, the former represent real gains, while the latter are fundamentally re-distributional in nature. 


\section{REFERENCES}

Akerlof, G., A. Rose, and J. Yellen. 1988. "Job Switching and Job Satisfaction in the US Labor Market," Brookings Papers on Economic Activity, 2, 495-594.

Bartik, T. J. 1991. Who Benefits from State and Local Economic Development Policies? Kalamazoo, MI: W.E. Upjohn Institute of Employment Research.

2000. Group Wage Curves. Kalamzoo, MI: W.E. Upjohn Institute of Employment Research Working Paper No. 00.63PC. Available at SSRN: http://ssrn.com/abstract=291196.

Blanchard, O. and P. Diamond. 1992. "The Flow Approach to Labor Markets," American Economic Review, 82(2), 354-359.

Blanchard, O. and L. F. Katz. 1992. "Regional Evolutions," Brookings Papers on Economic Activity, (1992)1, 1-75.

Blanchflower, D. G. and A. J. Oswald. 1994. The Wage Curve. Cambridge, MA: MIT Press.

Burgess, S., J. Lane, and D. Stevens. 1996. "Job Flows and Worker Flows: Issues and Evidence from a Panel of US Firms," in R. Schettkat (ed.), The Flow Analysis of Labor Markets London: Routledge, pp. 96-114.

Campbell, C. and J. M. Orszag. 1998. “A Model of the Wage Curve,” Economics Letters, 59, 119-125.

Card, D. 1995. “The Wage Curve: A Review," Journal of Economic Literature, 33(2), 785-799.

Eberts, R. and J. Stone. 1992. Wage and Employment Adjustment in Local Labor Markets. Kalamzoo, MI: W.E. Upjohn Institute of Employment Research.

Elhorst, J. P., U. Blien, and K. Wolf. 2007. "New Evidence on the Wage Curve: A Spatial Panel Approach," International Regional Science Review, 30(2), 173-191.

Forrest, R. and A. Murie. 1994. "The Dynamics of the Owner-Occupied Housing Market in Southern England in the Late 1980's: A study of New Building and Vacancy Chains," Regional Studies, 28(3), 275-290.

Gordon, I. 2006. Making (Spatial) Sense of the Wage Curve, paper presented at the 46th ERSA Congress, Volos, Greece.

Gorter, C. and R. Schettkat. 1999. On Musical Chair and Matching Models: Do Employed Job Seekers Crowd Out the Unemployed? Department of Regional Economics, Amsterdam: Free University.

Greenstone, M. and E. Moretti. 2003. "Bidding for Industrial Plants: Does Winning a 'Million Dollar Plant' Increase Welfare?” Working Paper 9844. Cambridge, MA: National Bureau of Economic Research. Available online at: http://www.nber.org/papers/w9844. accessed on 5/15/08.

Harris, J. R. and M. P. Todaro. 1970. "Migration, Unemployment and Development: A Two sector Analysis," American Economic Review, 60(1), 126-142.

Holt, C. and D. David. 1966. "The Concept of Job Vacancies in a Dynamic Theory of the Labor Market," in The Measurement and Interpretation of Job Vacancies. Cambridge, MA: National Bureau of Economic Research.

Longhi, S., P. Nijkamp, and J. Poot. 2006. "Spatial Heterogeneity and the Wage Curve Revisited," Journal of Regional Science, 46(4), 707-731.

Marshall, A. 1920. Principles of Economics (eighth edition). London: Macmillan.

Millard-Ball, A. 2002. "Gentrification in a Residential Mobility Framework: Social Change, Tenure Change and Chains of Moves in Stockholm," Housing Studies, 17(6), 833-856.

Morrison, P. S., K. L. Papps, and J. Poot. 2006. "Wages, Employment, Labour Turnover and the Accessibility of Local Labour Markets,” Labour Economics, 13(5), 639-663.

Mullen, J. K. and M. Williams. 2001. "Regional Efficiency Wages: Are they a Source of Real Earnings Differentials," Review of Urban and Regional Development Studies, 3, 244-260.

Nijkamp, P. and J. Poot. 2005. "The Last Word on the Wage Curve? A Meta-Analytic Assessment," Journal of Economic Surveys, 19, 421-450.

Persky, J. and D. Felsenstein. 2007. "Multipliers, Mark-Ups, and Mobility Rents: In Defense of 'Chain Models' in Urban and Regional Analysis," Environment and Planning A, forthcoming.

Persky, J., D. Felsenstein, and W. Wiewel. 1997. "How Do We Know that 'But-For the Incentives' the Development Would Not Have Occurred ?" in R. D. Bingham and R. Mier (eds.), Significant Issues in Urban Economic Development. Newbury Park, CA: Sage, pp. 28-46. 
Persky, J., D. Felsenstein, and V. Carlson. 2004. Does Trickle Down Work? Economic Development Strategies and Job Chains in Local Labor Markets. Kalamzoo, MI: W.E. Upjohn Institute of Employment Research.

Roback, J. 1982. "Wages, Rents and Quality of Life," Journal of Political Economy, 90(6), 1257-1277.

Schettkat, R. 1996. "Labor Market Dynamics in Germany," in R. Schettkat (ed.), The Flow Analysis of Labor Markets. London: Routledge.

Shapiro, C. and J. Stiglitz. 1984. "Equilibrium Unemployment as a Worker Discipline Device," American Economic Review, 74(3), 433-444.

Topel, R. H. 1986. "Local Labor Markets," Journal of Political Economy, 94(3), S111-S143.

Townsend, R. R. 2005. Choosing Among Competing Theories of the Wage Curve, Department of Economics, Stanford University, http://www-econ.stanford.edu/academics/Honors_Theses/ Theses_2005/Townsend.pdf 